\title{
Payer perceptions of the use of real-world evidence in oncology-based decision making
}

\author{
Diana Brixner, PhD, RPh; Joseph Biskupiak, PhD, MBA; Gary Oderda, PharmD, MPH; \\ Douglas Burgoyne, PharmD, FAMCP; Daniel C Malone, RPh, PhD, FAMCP; \\ Bhakti Arondekar, PhD, MBA; and Alexander Niyazov, PharmD, RPh, MPH
}

\section{What is already known about this subject}

- Payers use real-world data in decision making.

- How real-world evidence (RWE) is used depends on the available data and therapeutic area.

\section{ABSTRACT}

BACKGROUND: Randomized controlled trials (RCTs), the gold standard of safety and efficacy evidence, are conducted in select patients that may not mirror real-world populations. As a result, healthcare decision makers may have limited information when making formulary decisions, especially in oncology, given accelerated regulatory approvals and niche patient populations. Real-world evidence (RWE) studies may help address these

\section{What this study adds}

- Payers acknowledge RWE on innovative oncology products pre launch is limited, highlighting a need for more early communication with manufacturers under preapproval information exchange (PIE) rules.

- The types of RWE valued by payers both before and after launch included total cost of care, burden of illness, treatment patterns, subpopulations, adverse event profiles, off-label usage, and economic data for possible use in contracting.

- Payers appeared to be more engaged in conducting their own evaluations of RWE for oncology products than previously.

- The primary source of RWE data continues to be administrative claims, but many organizations are turning to electronic health records.

- Payers' interest in outcome-based contracting was high, despite the challenges to conducting these arrangements.

knowledge gaps and help inform oncology formulary decision making.

OBJECTIVE: To assess US payer perceptions regarding the use and relevance of RWE in informing oncology formulary decisionmaking.

METHODS: A national survey containing single-answer, multiple-answer, and freeresponse questions evaluated 4 key areas:

(1) the value of RWE, (2) barriers to RWE,

(3) sources of RWE, and (4) use of RWE in

\section{Author affiliations}

Diana Brixner, PhD, RPh; Joseph Biskupiak, PhD, MBA; Gary Oderda, PharmD, MPH; Douglas Burgoyne, PharmD, FAMCP; and Daniel C Malone, RPh, PhD, FAMCP, University of Utah, College of Pharmacy, Salt Lake City. Bhakti Arondekar, PhD, MBA, and Alexander Niyazov, PharmD, RPh, MPH, Pfizer, Inc.

\section{AUTHOR CORRESPONDENCE:}

Diana Brixner, 801.581.3182;

Diana.Brixner@utah.edu

J Manag Care Spec Pharm 2021;27(8):1096-105

Copyright $@ 2021$, Academy of Managed Care Pharmacy. All rights reserved.

outcomes-based contracting. The survey was distributed to 221 US payers through the Academy of Managed Care Pharmacy (AMCP) Market Insights program in February 2020. Ten additional respondents were invited to discuss the survey results. The survey results were presented primarily as frequencies of responses and were evaluated by the respondent's plan size, type, and geography (regional vs national). Differences in responses for categorical data were compared using a Pearson Chi-Square or a Fisher's Exact test. 
Two-tailed values are reported and a level of $\leq 0.05$ was used to indicate statistical significance.

RESULTS: The national survey had a 45.9\% response rate, with 106 payers responding. Most were from managed care organizations (MCOs; $47.5 \%$ ) and pharmacy benefit managers (PBMs; $37.4 \%$ ), with $54.5 \%$ from large plans ( $\geq 1$ million lives) and $45.5 \%$ from small plans (<1 million lives). Respondents were largely pharmacists (89.9\%), with $55.6 \%$ overall indicating their job was a pharmacy administrator. Most (84.9\%) used RWE to inform formulary decisions in oncology to support comparative effectiveness in the absence of head-to-head clinical trials ( 4.1 on a scale of $1=$ Not At All Useful to $5=$ Extremely Useful) and validation of National Comprehensive Cancer Network (NCCN) recommendations (4.0). Almost half (41.5\%) used RWE results to inform off-label usage decisions. Payers valued RWE pre-launch to inform formulary and contracting decisions and desired real-world comparative effectiveness data post-launch to validate coverage decisions. However, the majority of payers (54.7\%) did not conduct their own real-world studies. Commonly considered RWE sources included claims data (79.2\%), medical records (68.9\%), prospective cohort studies $(60.4 \%)$, patient registries $(36.8 \%)$, and patient outcome surveys (33.0\%). Barriers to conducting internal RWE studies included the lack of resources and personnel, analytic capabilities, appropriate in-house data, and perceived value in conducting analyses. Payers expressed interest in using outcomes-based contracting in oncology; few have direct experience, and operationalizing through value measurement is challenging.

CONCLUSIONS: RWE providing comparative treatment data, validation of NCCN treatment recommendations, and information on off-label usage are appreciated pre launch with post launch validation.

Innovative therapies for cancers are being introduced with growing frequency. Some of these therapies, especially those in areas with high unmet needs and limited patient populations, receive accelerated regulatory approvals, sometimes based on Phase II studies only or single-arm trials. In 2012, the US Food and Drug Administration Safety and Innovation Act was enacted to expedite the development and review of certain new drugs for serious or life-threatening diseases (sometimes designated as breakthrough drugs). ${ }^{1}$ This act allows promising drugs to receive accelerated approval based on surrogate markers of disease, while requiring that efficacy testing continues post-launch to confirm the initial results. A 2018 study showed that of drugs released in the US from 2012-2017, those designated as breakthrough drugs achieved first FDA approval in 5.2 years vs those designated as non-breakthrough drugs, which received first FDA approval in 7.1 years. ${ }^{2}$ As a result of accelerated approvals based on limited clinical trial data, however, payers are often forced to make oncology coverage decisions with limited information.

Despite the limited available data, payers must still use their resources efficiently and appropriately as they make coverage decisions. As a result, payers have turned to realworld evidence (RWE) to supplement traditional clinical trial data to help inform their oncology decision making. Recognizing that RWE is increasing in importance for differentiating therapies or treatment pathways as well as coverage decisions, and that payers desire such information to add to the clinical trial data, the FDA has issued guidance documents on the use of RWE to support regulatory decision making. ${ }^{3}$ Similarly, the National Comprehensive Cancer Network (NCCN) has integrated recommendations for RWE into their guidelines. ${ }^{4}$ Both of these actions have contributed to a growing number of RWE studies being published by manufacturers and researchers.

Despite the growing interest in and production of RWE, there is still limited information on how RWE is actually used by US payers in their decision making. Although the understanding of RWE in general healthcare decision making has been examined in the literature, ${ }^{5}$ very little has been published on the use of RWE specifically in oncology decision making.

This study was conducted to expand the understanding of how payers in the US use RWE to inform healthcare decision making in oncology. This information can help payers identify and prioritize relevant RWE from researchers and help manufacturers design RWE studies that would be relevant to payers.

\section{Methods}

An interdisciplinary steering committee of payers, academics, and industry health economics and outcomes research (HEOR) experts was formed to develop a survey to gauge payer understanding of the value and use of RWE in oncology coverage decision making.

The steering committee created a pilot survey based on literature reviews and current understanding of the payer landscape regarding the use of RWE in oncology decision making. The pilot survey was distributed via email to 5 US payers in October 2019. The results were tallied, then a follow-up in-person discussion was held a week later with the steering committee and the 5 payers. Discussions focused on questions where the answers showed disagreement or confusion. Survey questions were revised based on feedback from the payers, then reviewed by the authors prior to distribution. 


\section{TABLE 1 Demographics of Survey Respondents}

\begin{tabular}{|c|c|c|c|c|c|c|c|}
\hline & \multicolumn{2}{|c|}{$\begin{array}{l}\text { Total } \\
\mathbf{N}(\%)\end{array}$} & \multicolumn{2}{|c|}{$\begin{array}{c}\text { Small } \\
\text { (<1 million } \\
\text { lives covered) } \\
\mathbf{N}=45 \\
\mathbf{n}(\%)\end{array}$} & \multicolumn{2}{|c|}{$\begin{array}{c}\text { Large } \\
\text { ( } \geq 1 \text { million } \\
\text { lives covered) } \\
\mathbf{N}=54 \\
\mathbf{n}(\%)\end{array}$} & \multirow[t]{2}{*}{$P$ value } \\
\hline \multicolumn{7}{|l|}{ Organization type $(n=99)^{a}$} & \\
\hline Managed care organization & 47 & $(47.5)$ & 24 & $(53.3)$ & 23 & $(42.6)$ & 0.317 \\
\hline Pharmacy benefit manager & 37 & $(37.4)$ & 11 & $(24.4)$ & 26 & $(48.1)$ & 0.021 \\
\hline Employer group & 12 & $(12.1)$ & 8 & $(17.8)$ & 4 & $(7.4)$ & 0.134 \\
\hline Government & 9 & $(9.1)$ & 8 & $(17.8)$ & 1 & (1.9) & 0.010 \\
\hline Integrated delivery network & 10 & $(10.1)$ & 7 & $(15.6)$ & 3 & $(5.6)$ & 0.178 \\
\hline Health management organization & 8 & $(8.1)$ & 5 & $(11.1)$ & 3 & $(5.6)$ & 0.463 \\
\hline Accountable care organization & 5 & $(5.1)$ & 3 & $(6.7)$ & 2 & $(3.7)$ & 0.657 \\
\hline Other & 5 & $(5.1)$ & 3 & $(6.7)$ & 2 & (3.7) & 0.657 \\
\hline \multicolumn{8}{|l|}{ Region of united states $(n=89)$} \\
\hline Northeast & 26 & $(29.2)$ & 9 & $(21.4)^{\mathrm{b}}$ & 17 & $(36.2)$ & 0.253 \\
\hline Midwest & 25 & $(28.1)$ & 10 & $(23.8)$ & 15 & (31.9) & 0.644 \\
\hline West & 25 & $(28.1)$ & 14 & $(33.3)$ & 11 & $(23.4)$ & 0.251 \\
\hline South & 13 & (14.6) & 9 & (21.4) & 4 & (8.5) & 0.079 \\
\hline
\end{tabular}

Regional vs national $(\mathrm{n}=99)$

\begin{tabular}{l|rr|rr|rr|r}
\hline Regional & 49 & $(49.5)$ & 35 & $(77.8)$ & 14 & $(25.9)$ & $<0.001$ \\
\hline National & 47 & $(47.5)$ & 8 & $(17.8)$ & 39 & $(72.2)$ & $<0.001$ \\
\hline Other & 3 & $(3.0)$ & 2 & $(4.4)$ & 1 & $(1.9)$ & 0.589
\end{tabular}

\begin{tabular}{l|rl|rr|rr|l}
\hline Payer type $(\mathbf{n}=99)$ & 64 & $(64.6)$ & 21 & $(46.7)$ & 43 & $(79.6)$ & 0.001 \\
\hline Commercial + government & 19 & $(19.2)$ & 13 & $(28.9)$ & 6 & $(11.1)$ & 0.039 \\
\hline Government & 16 & $(16.2)$ & 11 & $(24.4)$ & 5 & $(9.3)$ & 0.055 \\
\hline Commercial &
\end{tabular}

continued on next page

The revised survey questions included 18 single-answer, multipleanswer, and free-response questions about payer perceptions and use of RWE. Some questions asked for Yes/ No responses, some specified to select one or more responses from a given list, some allowed selection of a single choice from a given list, and one asked respondents to rank choices on a scale of $1=$ Not at all Useful to $5=$ Extremely Useful. Of the 18 final RWE-relevant questions, 7 addressed the value of RWE (the types of decisions that can be informed by RWE in oncology, and how organizations used RWE in oncology formulary decision making), 5 focused on the source of RWE (specifically internal vs external sources), 2 asked respondents to identify barriers to conducting their own real-world analyses, and 4 explored respondents' experience in outcomesbased contracting and their interest in using RWE to inform outcomes-based contracting.

Subsequently, in February 2020, the national on-line survey was distributed through the Academy of Managed Care Pharmacy (AMCP)
Market Insights program to a panel of 221 payers in the United States. This managed care panel consists of AMCP members who are pharmacy leaders involved in medication product evaluation and/or utilization management who have agreed up front to participate in payer-based market research. Responses to the online survey were collected using SurveyMonkey.

The same survey was also distributed to 10 US payers who agreed to participate in a live panel discussion about the aggregate survey results. The survey results from these 10 panelists were combined with the results from the broader payer panel mentioned above. Before the panel discussion, each panelist was sent a 2018 article on the use of RWE in US payer decision making (non-oncologyspecific) to provide a common basic level of understanding around RWE. ${ }^{5}$ The panel of 10 payers and the steering committee members convened virtually in March, 2020, to discuss survey findings.

\section{SURVEY ANALYSIS AND STATISTICS}

The survey results were presented primarily as frequencies of responses. Dummy variables (yes/ no) were created for each response on the multiple response questions. Categorical responses were evaluated using Pearson Chi-Square or Fisher's exact test by plan size, plan type, and scope of service (regional vs national). Statistical significance was based on two-tailed values with a level of $\leq 0.05$.

\section{Results}

\section{DEMOGRAPHICS OF RESPONDENTS}

From the national sample of $221 \mathrm{AMCP}$ survey respondents plus 10 payer panelists, 106 completed the survey, resulting in a $45.9 \%$ response rate. Table 1 shows key demographics of the 


\section{TABLE 1 Demographics of Survey Respondents (continued)}

\begin{tabular}{|c|c|c|c|c|}
\hline & $\begin{array}{l}\text { Total } \\
\text { N (\%) }\end{array}$ & $\begin{array}{c}\text { Small } \\
(<1 \text { million } \\
\text { lives covered) } \\
\mathbf{N}=45 \\
\mathbf{n}(\%)\end{array}$ & $\begin{array}{c}\text { Large } \\
\text { ( } \geq 1 \text { million } \\
\text { lives covered) } \\
\mathbf{N}=54 \\
n(\%)\end{array}$ & $P$ value \\
\hline \multicolumn{5}{|l|}{ Degrees $(n=99)^{a}$} \\
\hline RPH, PharmD & $89 \quad(89.9)$ & $39 \quad(86.7)$ & $50 \quad(92.6)$ & 0.505 \\
\hline MS, MBA, MPH & $30 \quad(30.3)$ & $13 \quad(28.9)$ & $17 \quad(31.5)$ & 0.829 \\
\hline MD, DO & $4 \quad(4.0)$ & $2 \quad(4.4)$ & $(3.7)$ & 1.000 \\
\hline PhD & $2 \quad(2.0)$ & $1 \quad(2.2)$ & $(1.9)$ & 1.000 \\
\hline Other & $(3.0)$ & $(6.7)$ & $(0.0)$ & 0.090 \\
\hline \multicolumn{5}{|l|}{ Position $(n=99)$} \\
\hline Pharmacy administrator & $55 \quad(55.6)^{b}$ & $26 \quad(57.8)$ & $29 \quad(53.7)$ & 0.839 \\
\hline Pharmacist & $30 \quad(30.3)$ & $12(26.7)$ & $18 \quad(33.3)$ & 0.516 \\
\hline Medical director & $5 \quad(5.1)$ & $2 \quad(4.4)$ & $(5.6)$ & 1.000 \\
\hline Other & $(9.1)$ & $5 \quad(11.1)$ & $(7.4)$ & 0.728 \\
\hline \multicolumn{5}{|l|}{ Time in position $(n=99)$} \\
\hline$<1$ year & $8 \quad(8.1)$ & $5 \quad(11.1)$ & $(5.6)^{b}$ & 0.463 \\
\hline $1-5$ years & $50 \quad(50.5)$ & $23 \quad(51.1)$ & $27 \quad 50.0)$ & 1.000 \\
\hline 6-10 years & $18 \quad(18.2)$ & $5 \quad(11.1)$ & $13 \quad(24.1)$ & 0.120 \\
\hline$>10$ years & $23 \quad(23.2)$ & $12(26.7)$ & 11 (20.4) & 0.483 \\
\hline
\end{tabular}

respondents. The most common organizations represented were managed care organizations (MCOs; 47.5\%) and pharmacy benefit managers (PBMs; $37.4 \%)$, with plans evenly divided between regional (49.5\%) and national (47.5\%) plans. Private payer plans covering commercial and government lives represented $64.6 \%$ of the respondents' organizations. There was good representation across small, medium, and large plans, with $24.2 \%$ of respondents representing plans with $\geq 10$ million members. Most respondents were pharmacists (89.9\%). The most common roles included pharmacy administrators (55.6\%) and pharmacists/clinical pharmacists (30.3\%). Over half (58.6\%) of respondents had been with their current organization for $\leq 5$ years.
The results are organized by 4 key categories: (1) the current state of RWE use in oncology decision making by payers, (2) the sources of RWE used by payers in oncology decision making, (3) barriers to the use of RWE in oncology decision making, and (4) the use of RWE to support outcomes-based contracting in payer reimbursement and benefit design decisions.

\section{THE CURRENT STATE OF RWE USE}

Most payers (84.9\%) reported they use RWE to inform formulary decisions in oncology. When asked to rank the usefulness of RWE in informing formulary decision making for oncology products in various applications, respondents indicated that they perceive RWE's highest usefulness in assessing comparative effectiveness where head-to-head clinical trials are not available (4.1) and in support of evidence to inform National Comprehensive Cancer Network (NCCN) and other guidelines (4.0). While still perceived as "somewhat useful," payers ranked "historical controls for single-arm clinical trials" the least useful (2.9) on the provided list (see Figure 1.) Payers ranked the use of RWE for off-label formulary decision making in oncology as 6th in the same list, with $41.5 \%$ saying their organization was extremely or somewhat likely to use RWE results to inform off-label usage decisions.

When the 10 payer panelists met to discuss the survey findings, they offered additional insights. They agreed that in oncology, the interest in using RWE for decision making is high and growing, especially for comparative effectiveness, formulary placement, and financial considerations. They also indicated that for initial placement and coverage decisions in oncology, any RWE provided to $\mathrm{P} \& \mathrm{~T}$ committees is often considered, in addition to data from randomized control trials (RCTs) and expert feedback. After a product has been launched, class-related and/or product-specific RWE may be used to reevaluate decisions or treatment sequencing (or treatment pathways) as such data becomes available.

\section{SOURCES OF RWE}

Payers reported using a variety of RWE from both internal and external sources. Claims data was reported to be considered by $79.2 \%$ of organizations; medical records data is particularly important in oncology RWE and was reported to be used by $68.9 \%$ of respondents. Nearly twothirds (60.4\%) of respondents indicated that they also use data from prospective cohort studies. Patient registries and patient outcome surveys were 


\section{FIGURE 1 US Payers' Ranking of the Usefulness of Types of RWE Studies for Informing Oncology Decision Making (Mean Values Shown)}

Question: Please describe the usefulness of the following using a response scale from Extremely Useful to Not at All Useful to inform formulary decision-making for oncology products. $\mathbf{N}=\mathbf{9 9}$

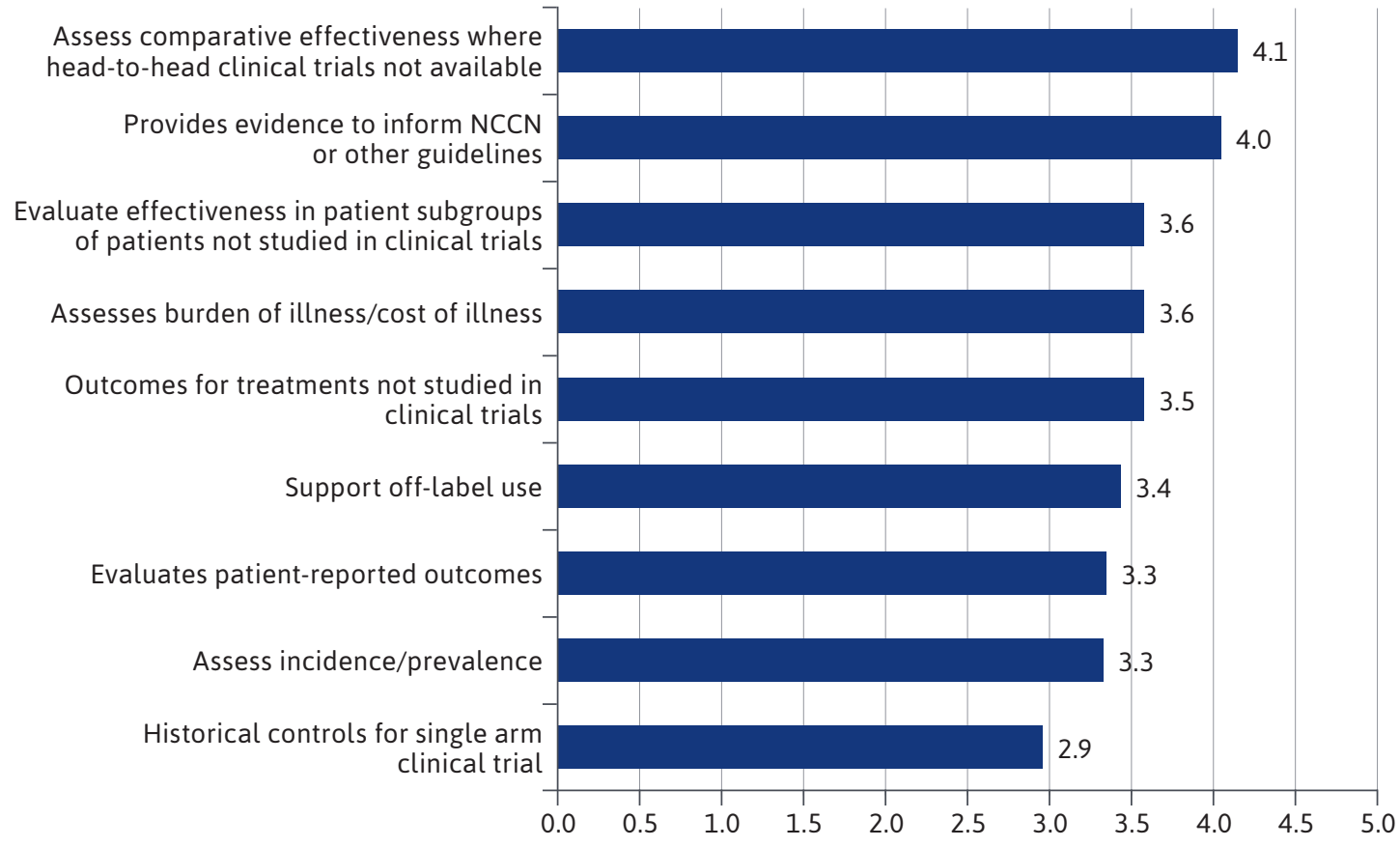

each used in about one third of organizations $36.8 \%$ and $33.0 \%$ respectively). PBMs and MCOs were similar in regard to the types of data they would consider, including medical records, claim data, and patient outcomes surveys. MCOs were more likely to consider prospective cohort studies than PBMs (66.0\% vs 56.8\%) and more likely to consider patient registries (42.6\% vs $27.0 \%$ ).

The majority of respondents indicated they do not conduct their own real-world studies to inform oncology coverage decisions More large plans ( $\geq 1$ million members) indicated they were conducting their own real-world studies, but this was not significantly different from small plans (<1 million members; $48.1 \%$ vs $40.0 \%$; $\mathrm{P}=0.417$ ). When plans do conduct their own studies, it is most often used to populate budget impact models (BIMs) or cost-effectiveness models (CEMs) with their own data (53.8\% of large plans, $72.2 \%$ of small plans, $P=0.218$ ). Large plans were more likely than small plans to use real-world studies to validate RCT findings within their own populations (69.2\% vs $33.3 \%$, $\mathrm{P}=0.019)$ and to support off-label use (24.1\% vs $13.3 \%$,
$P=0.0177)$. Similarly, MCOs and PBMs reported differences in RWE utilization, with MCOs more likely to conduct RWE studies than PBMs (56.8\% vs $43.2 \%, \mathrm{P}=0.505)$. Of MCOs that do conduct RWE studies in oncology, 38.3\% conduct studies to validate RCT findings, $25.5 \%$ do it to support off-label use, and $31.9 \%$ populate internal BIMs and CEMs.

When asked why most payers use pharmacy and medical claims for RWE data, the panelists agreed it was due to the availability of claims data. However, the use of electronic health records (EHRs) is growing, and the panelists expected to see that trend continue. They indicated that PBMs often have less access to medical data or medical records, and they must often rely upon pharmacy claims data. The sole use of pharmacy claims data was seen as problematic for oncology decision making because of the lack of clinical or other information beyond dose strength and duration of therapy.

When seeking RWE from outside of the organization, panelists agreed that the most common way to find RWE is via literature searches or from manufacturer discussions. 


\section{FIGURE 2 Barriers to Conducting in-House RWE Studies}

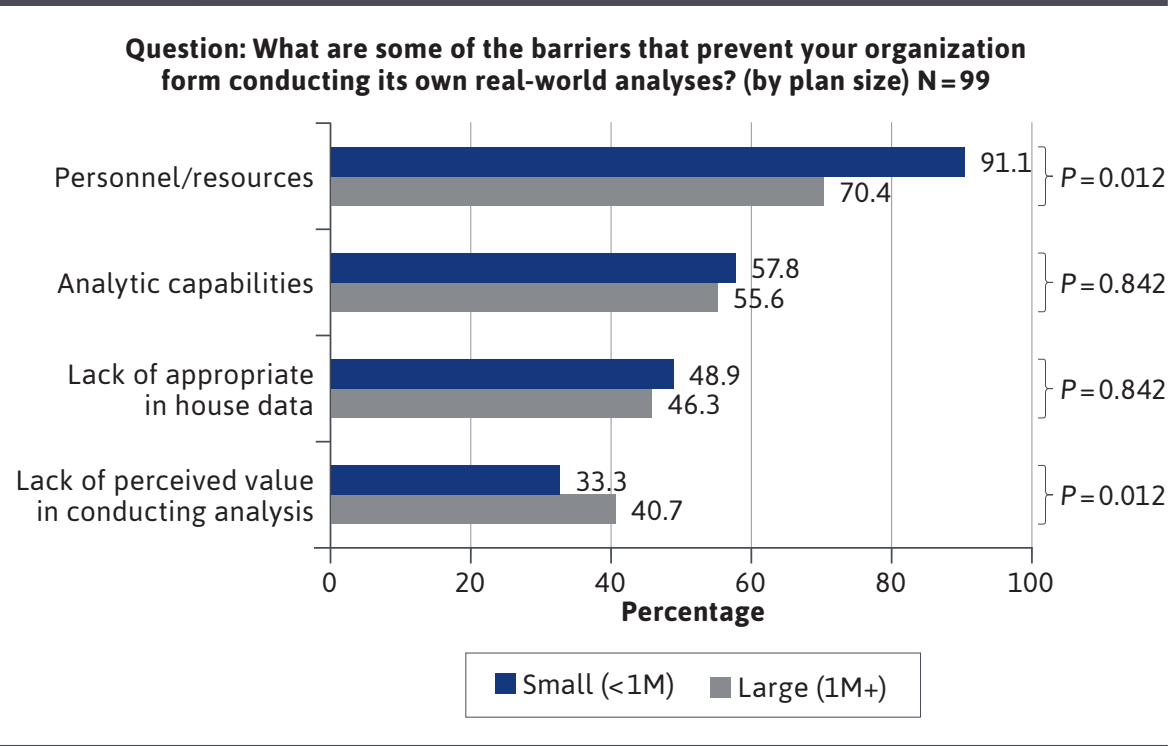

\section{BARRIERS TO USING RWE}

Payers were asked to rank a list of potential barriers to conducting their own RWE studies (see Figure 2). The largest reported barrier was a lack of resources and personnel, which was a smaller concern for large plans than small plans $(70.4 \%$ vs $91.1 \%, P=0.012)$.

Other barriers were viewed similarly between large and small payers, with no statistical difference in responses. More than half of respondents reported a lack of analytic capabilities as a significant barrier (55.6\% of large plans vs $57.8 \%$ of small plans, $P=0.824)$. Similarly, almost half of payers cited lack of appropriate in-house data $(46.3 \%$ of large plans vs $48.9 \%$ of small plans, $P=0.797$ ) as a barrier. There were significant differences between large and small plans in what data they used for RWE $(P=0.037)$. Large plans were more likely to have access to claims data (85.2\% vs $68.9 \%, P=0.088)$ and medical records $(77.8 \%$ vs $57.8 \%, P=0.049)$ than small plans . In addition, at least one-third of all plans responded that the lack of perceived value in conducting analyses is a barrier to conducting their own RWE studies (40.7\% of large plans vs $33.3 \%$ of small plans, $P=0.533$ ).

When panelists were asked why some plans question the value of conducting in-house RWE studies, they agreed the cost of producing RWE is prohibitive. Given the small eligible patient population oncology for some innovative drugs, payers expressed concerns about the worth of conducting in-house research. Instead, payers stated they often look to NCCN or other professional societies to incorporate RWE into published guidelines, thereby minimizing their own effort and expense of producing in-house RWE. Given the small number of oncology patients, payers with available in house data and necessary analytic capabilities were worried about whether the data produced would be meaningful or actionable.

\section{OUTCOMES-BASED CONTRACTING}

Organizations have significant interest in using RWE to inform outcomes-based contracting, with three-quarters (76.5\%) saying they are moderately, very, or extremely interested, and $17.6 \%$ saying they were somewhat interested. Only $5.9 \%$ said they had no interest (see Figure 3). More payers from large plans covering $\geq 1$ million lives expressed interest than from smaller plans $(48.1 \%$ vs $28.9 \%$. $P=0.043)$. These differences in the use of outcomes-based contracting by plan size were statistically significant.

Despite the high interest, less than 1 in 5 organizations (17.2\%) reported having experience in using outcomes-based contracting in oncology. Large plans appear to have had more experience than small plans in implementing these contracts $(25.9 \%$ vs $6.7 \%, P=0.015)$. These differences in use of outcomes-based contracting by plan size are statistically significant.

Payers perceived a variety of barriers to implementing outcomes-based contracting within their organizations (Figure 4). The most significant barriers included challenges around the definition of outcomes to be measured and monitored over time (76.5\%) and the complexity of outcomes-based agreements (74.5\%). Nearly half of payers $(48.0 \%)$ revealed that the cost of implementing such agreements is a challenge, the same number $(48.0 \%)$ believe the small size of the targeted population is a barrier, and $34.3 \%$ cite a lack of personnel.

The panelists agreed that interest in outcomes-based contracting in oncology is growing, but there is significant uncertainty around how to operationalize and capture the data for these contracts. They agreed that the definitions of outcomes and endpoints are key, yet difficult and complex to measure because they can be affected by adherence, proxy measures, co-morbidities, hospitalizations, relapses, etc.

In addition, not all of this data may be readily accessible to all health plans, complicating an organization's 


\section{FIGURE 3 US Payer Interest in Using RWE to Inform Outcomes-Based Contracting}

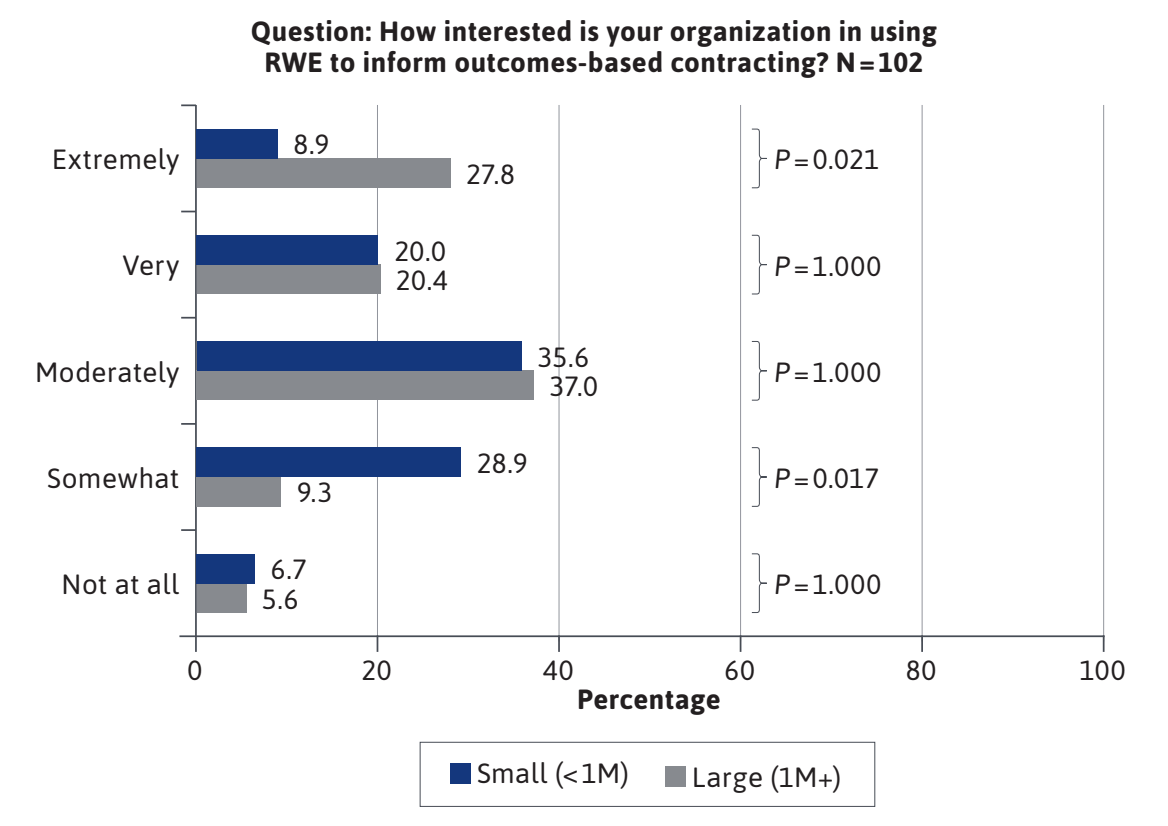

ability to measure and track the necessary data. Outcomes-based contracting requires visibility into both the pharmacy and medical sides to see short-term and long-term impacts on hospitalizations, procedures, toxicities, and overall survival (OS) and progression-freesurvival(PFS) rates. ${ }^{6-11}$ PBMs, for example, may not have access to medical data to adequately measure value for outcomes-based contracting.

However, the rate of access to this crucial information is expected to grow in the future, particularly in light of the trend to vertical integration, with recent mergers of PBMs with health plans and the growth in accountable care organizations (ACOs) and integrated plans. As vertically integrated organizations facilitate internal access to patient data, the ability of these organizations to implement outcomes-based or value-based contracting may increase. ${ }^{12-14}$
Payers expressed uncertainty about the most effective ways to implement contracting agreements (eg, volumebased vs outcomes-based, rebates after reconciliation or discounts up front, etc.). They also were concerned with how to cross-walk evidence and data from the study population to other subpopulations within their plans.

Panelists expressed concern that because of the small populations involved with some oncology products, and the fact that clients may be unable to see or understand results from any changes created by outcomes-based contracts, the return on investment for outcomes-based contracting is sometimes seen as a significant challenge.

\section{Discussion}

The results of this study suggest that many US payers are using real-world data in their efforts to improve costs and outcomes in oncology, and they find RWE is useful in informing oncology formulary decisions.

While manufacturers often generate a variety of RWE, US payers initially are focused on comparative effectiveness evidence, considering this the most useful for differentiating a new entry vs standard of care, given that RCTs can fall short in providing this data. However, payers are also interested in other types of RWE that manufacturers can generate, such as total cost of care, burden of illness, treatment patterns, subpopulations, adverse event profiles, off-label usage, and economic data for possible use in contracting. The use of RWE in these various capacities is likely to grow. One reason for this likely growth is that RWE generation has become more robust in recent years. As the Food and Drug Administration and professional societies such as the NCCN have incorporated RWE expectations into guidelines and recommendations, ${ }^{3,4,15}$ RWE studies are becoming more structured and consistent. For example, the 21st Century Cures Act directed the FDA to evaluate the potential use of real-world evidence (RWE) to (1) support the approval of a new indication for a drug approved under section 505(c) of the Federal Food, Drug, and Cosmetic Act; and (2) to support or satisfy post-approval study requirements. ${ }^{16}$ Payers may benefit from taking a renewed look at the level of RWE being generated today.

Additionally, advancing technology is making real-world data more accessible for researchers to access and conduct meaningful studies. US payers consider RWE valuable at all phases of a product's life cycle. Payers access RWE using literature searches, and are also interested in RWE generated by manufacturers both pre-launch and post-launch. 


\section{FIGURE 4 Perceived Barriers to Implementing Outcomes-Based Contracting Within US Payers' Organizations}

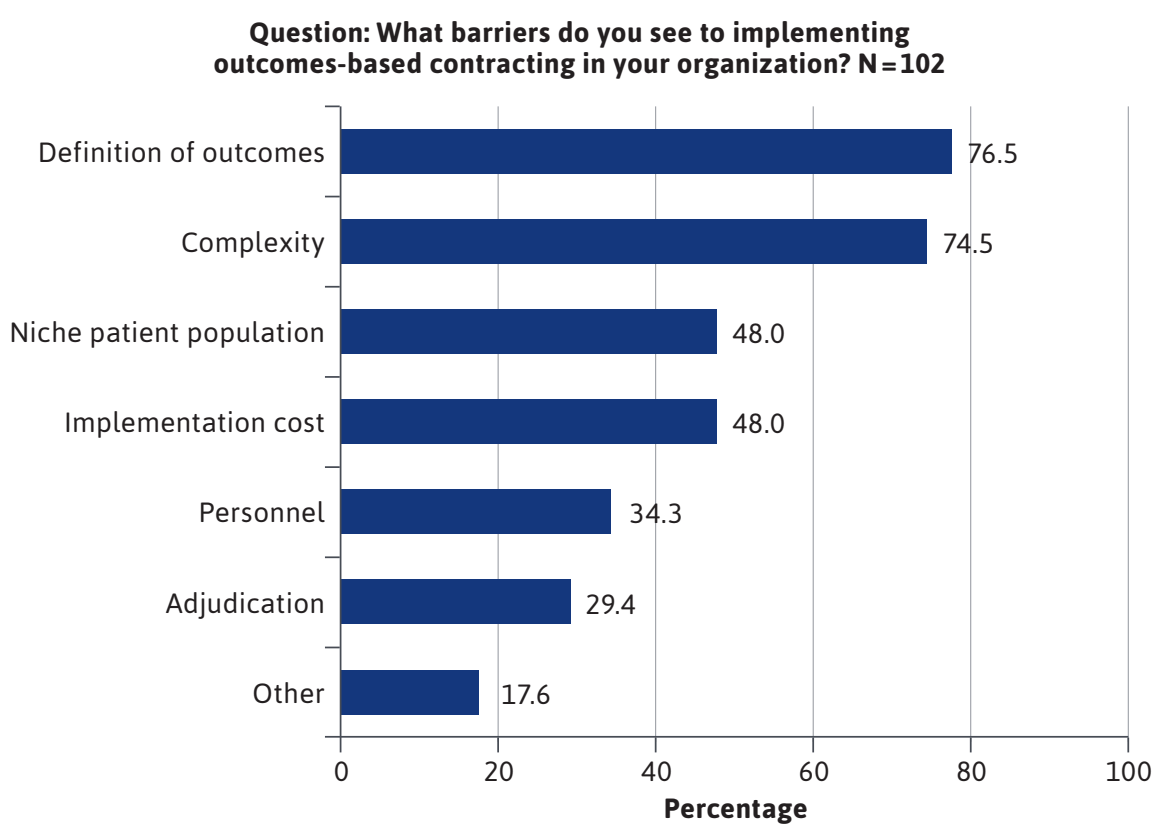

Pre-launch RWE is desirable because it can be delivered to P\&T committees along with RCT data and expert feedback. However, payers were significantly concerned that comparative effectiveness RWE on a new product is generally not available at the time of launch, and a certain amount of uptake is required prior to seeing RWE studies in the literature or generated by individual health plans. Therefore, payers would benefit by seeing additional types of RWE such as disease prevalence and cost, current treatment patterns and standard of care, and adverse event profiles to better understand the appropriate positioning of a new product. While this type of RWE is often available from clinical trials, the payer panelists reported that they seldom see it. This highlights an opportunity for payers to use preapproval information exchange (PIE) guidelines ${ }^{17,18}$ to request
RWE from manufacturers prior to the launch of a new product.

Post-launch RWE may be used to reevaluate decisions or treatment pathways; therefore, manufacturers, payers, and researchers should continue to prioritize RWE before and after launch.

Internally, payers who conduct their own RWE studies or validate RWE studies using their own data often use medical and pharmacy claims data because of ready availability, but they acknowledged the limitations of such data in deducing treatment patterns, identifying progression-free and overall survival, and generating comparative effectiveness evidence. For this reason, the use of electronic health records (EHRs) in oncology is growing. For example, a recent survey of US hematology/oncology clinical pharmacists revealed that respondents reported they spend $84.1 \%$ of their workdays working in electronic health records, an increased utilization of technology over the previous 5 years. Further, the study showed pharmacists felt patient care is safer, of better quality, and more efficient with the advance of EHR technology. ${ }^{19}$ However, EHRs present challenges for consistent data extraction due to their often unstructured and incomplete nature. ${ }^{20,21}$ This emphasizes the need for more robust EHR design and the integration of EHR with claims data.

Payers also mentioned that realworld evidence can be used to support the off-label use of medications where payers ordinarily would not provide coverage. CMS will consider reimbursement for off-label uses of drugs and biologics in an anticancer chemotherapeutic regime if the therapy is included in a compendia. ${ }^{22}$

The increasing desire for and growing robustness of RWE research and technology highlights an opportunity for collaborative work between payers, manufacturers, researchers, and other stakeholders. There is a clear need for understanding what research questions are important to payers, physicians, and patients and how data can be accessed to find answers to those questions. Upfront, early discussions (under PIE) between payers and manufacturers can help target research resources towards payerrelevant evidence that is considered impactful in coverage or contracting decisions, especially in areas such as total cost of care, burden of illness, treatment patterns, subpopulations, adverse event profiles, and economic data for possible use in contracting.

With the RWE field still developing, payers and manufacturers should work together to develop best practices for incorporating various types of RWE into initial decision making and post-launch reviews. There is also an educational opportunity for both payers and physicians to learn more about the expanded use of RWE and 
its potential impact in multiple areas related to oncology decision making, especially in light of the rapidly changing RWE landscape.

A growing body of evidence suggests the use of outcomes-based contracts is expanding and should continue to be evaluated for their value. $^{6,23,24}$ While interest in outcomes-based contracting is high, confidence in how to operationalize such contracts is still nascent. Therefore, payers and manufacturers have an opportunity to work together to refine measurable definitions of endpoints and outcomes, value measures, and other variables with an eye towards defining best practices. That may help contracting be viewed as a useful tool instead of a questionable use of resources.

\section{LIMTATIONS}

Although many organizations that provide services to millions of lives participated in the study, the data may not be generalizable to all health plans. In particular, integrated delivery systems were not well represented in this survey. The majority of respondents were pharmacy directors of health plans; other decision makers, such as medical directors, may have a different perspective. This survey was conducted among US payers, so payers or reimbursement organizations from outside the United States may have different perspectives. Additionally, only a small portion (approximately $10 \%)$ of the respondents participated in the virtual panel discussions; therefore, their opinions may not represent all respondents.

\section{Conclusions}

Payers in the United States value RWE as an important part of the evidence portfolio in healthcare decision making in oncology. This is particularly true for innovative oncology products for small, niche populations with high unmet needs because RWE can support the traditional evidence that is often limited in this category due to frequent accelerated approval.

The timing of RWE availability in making formulary and contracting decisions in oncology is a significant issue. US payers value early discussions with manufacturers on payer-relevant RWE well before launch, because such evidence can help payers determine the appropriate placement of new oncology therapies within populations most likely to respond to proposed treatment pathways. Payers also want to see additional real-world comparative effectiveness data post-launch to validate assumptions and coverage decisions.

Many payers are concerned about the expense and effort of conducting their own RWE studies internally; therefore, many rely on RWE being integrated into guidelines from the NCCN. They are also interested in seeing RWE presented in the literature.

As RWE is increasingly valued as a component of effective decision making in oncology, a significant educational need and opportunity exists for payers to learn about the potential impact of more broadly defined RWE to inform formulary decisions in oncology.

\section{DISCLOSURES}

Pfizer provided funding for this research, and employees of Pfizer led the development of the survey and contributed to the manuscript as authors. Arondekar and Niyazov are employees of Pfizer; Oderda, Biskupiak, and Brixner are managers of Millcreek Outcomes Group and were paid as consultants on this project. Burgoyne was a consultant for Pfizer on this project. Malone was paid by Millcreek Outcomes as a consultant on this project.

\section{ACKNOWLEDGMENTS}

The authors acknowledge medical writer Kelley J. P. Lindberg for her assistance in editing this manuscript, which was funded by Millcreek Outcomes.

\section{REFERENCES}

1. Food and Drug Administration Safety and Innovation Act. Pub L. No. 112-144, 126 Stat. 993. (2012) https://www.congress. gov/112/plaws/publ144/PLAW-112publ144. pdf

2. Hwang TJ, Franklin JM, Chen CT, et al. Efficacy, safety, and regulatory approval of Food and Drug Administrationdesignated breakthrough and nonbreakthrough cancer medicines. J Clin Oncol. 2018;36(18):1805-1812.

3. US Food and Drug Admininstration. Use of real-world evidence to support regulatory decision-making for medical devices: guidance for industry and Food and Drug Administration staff. Published August 31, 2017. https://www.fda.gov/media/99447/ download

4. National Comprehensive Cancer Network. NCCN clinical practice guildelines in oncology (NCCN guidelines). https://www.nccn.org/professionals/ physician gls/default.aspx

5. Malone DC, Brown M, Hurwitz JT, Peters L, Graff JS. Real-world evidence: useful in the real world of US payer decision making? How? When? And what studies? Value Health. 2018;21(3):326-33.

6. Kefalas P, Ali O, Jørgensen J, et al. Establishing the cost of implementing a performance-based, managed entry agreement for a hypothetical CAR T-cell therapy. J Mark Access Health Policy. 2018;6(1):1511679.

7. Yu JS, Chin L, Oh J, Farias J. Performance-based risk-sharing arrangements for pharmaceutical products in the United States: a systematic review. J Manag Care Spec Pharm. 2017;23(10):1028-40.

8. AMCP Partnership Forum: Driving value and outcomes in oncology. J Manag Care Spec Pharm. 2017;23(5):591-97. 
9. Kudrin A. Reimbursement challenges with cancer immunotherapeutics. Hum Vaccin Immunother. 2012;8(9):1326-34.

10. Pauwels K, Huys I, Vogler S, Casteels M, Simoens S. Managed entry agreements for oncology drugs: lessons from the European experience to inform the future. Front Pharmacol. 2017;8:171.

11. Gonçalves FR, Santos S, Silva C, Sousa G. Risk-sharing agreements, present and future. Ecancermedicalscience. 2018;12:823.

12. Hogan TH, Lemak CH, Ivankova N, Hearld LR, Wheeler J, Menachemi N. Hospital vertical integration into subacute care as a strategic response to value-based payment incentives, market factors, and organizational factors: a multiple-case study. Inquiry. 2018;55:46958018781364.

13. Heeringa J, Mutti A, Furukawa MF, Lechner A, Maurer KA, Rich E. Horizontal and vertical integration of health care providers: a framework for understanding various provider organizational structures. Int J Integr Care. 2020;20(1):2.

14. Hanna J. Vertical integration in health care: the next stairway to heaven? Pharmacy Times. Published July 16, 2019. Accessed May 2, 2020. https:// www.pharmacytimes.com/news/ vertical-integration-in-health-care-thenext-stairway-to-heaven
15. US Food and Drug Administration. Submitting documents using real-world data and real-world evidence to FDA for drugs and biologics. Guidance for industry. Published May 2019. Accessed May 4, 2020. https://www.fda.gov/ media/124795/download

16. US Food \& Drug Administration. Considerations for the use of real-world evidence to assess the effectiveness of preventative vaccines. https://www.fda. gov/vaccines-blood-biologics/workshops-meetings-conferences-biologics / considerations-use-real-world-evidenceassess-effectiveness-preventive-vaccines-09172020-09182020

17. Brixner D, Woodward TC, Seifter N, et al. Preapproval information exchange: perspectives of US population health decision makers on preferences for early engagement with investigational therapies. J Manag Care Spec Pharm. 2019;25(2):164-73.

18. AMCP Partnership Forum: Enabling the exchange of clinical and economic information pre-FDA approval. J Manag Care Spec Pharm. 2017;23(1):105-12.

19. Phillipon JS, Kusoski CL, Kennerly-Shah JM, Barreto JS. Describing the role of the hematology/oncology clinical pharmacist in health information technology. J Oncol Pharm Pract. 2020. doi:10.1177/1078155220908924. [Epub ahead of print].
20. Bertagnolli MM, Anderson B, Quina A, Piantadosi S. The electronic health record as a clinical trials tool: opportunities and challenges. Clin Trials. 2020. doi:10.1177/1740774520913819. [Epub ahead of print].

21. Lin J, Jiao T, Biskupiak JE, McAdam-Marx C. Application of electronic medical record data for health outcomes research: a review of recent literature. Expert Rev Pharmacoecon Outcomes Res. 2013;13(2):191-200.

22. Centers for Medicare \& Medicaid Services. Compendia 1861 (t)(2)-anticancer. https://www.cms.gov/Medicare/ Coverage/CoverageGenInfo/compendia

23. Gupta R, Roh L, Lee C, et al. The population health value framework: creating value by reducing costs of care for patient subpopulations with chronic conditions. Acad Med. 2019;94(9):1337-42.

24. Lorente R, Antonanzas F, Rodriguez-Ibeas R. Implementation of risk-sharing contracts as perceived by Spanish hospital pharmacists. Health Econ Rev. 2019;9(1):25. 